Article

\title{
Audience Views on Professional Norms of Journalism. A Media Repertoire Approach
}

\author{
Pauljan Truyens *(1) and Ike Picone $\mathbb{( 1 )}$ \\ Department of Communication Sciences, Vrije Universiteit, 1050 Brussel, Belgium; ike.picone@vub.be \\ * Correspondence: pauljan.truyens@vub.be
}

Citation: Truyens, Pauljan, and Ike

Picone. 2021. Audience Views on

Professional Norms of Journalism. A

Media Repertoire Approach.

Journalism and Media 2: 258-274.

https://doi.org/10.3390/

journalmedia2020015

Academic Editor:

Andreu Casero-Ripollés

Received: 3 May 2021

Accepted: 3 June 2021

Published: 8 June 2021

Publisher's Note: MDPI stays neutral with regard to jurisdictional claims in published maps and institutional affiliations.

Copyright: (c) 2021 by the authors. Licensee MDPI, Basel, Switzerland. This article is an open access article distributed under the terms and conditions of the Creative Commons Attribution (CC BY) license (https:// creativecommons.org/licenses/by/ $4.0 /)$.

\begin{abstract}
Despite several studies showing discrepancies between audience expectations of journalism and journalists' professional norms, what remains largely unknown is the audience view on the adherence of journalism to these seemingly essential professional norms. Recent research mainly focused on analysing audience expectations within the context of specific cases. Moreover, these studies rarely take into consideration characteristics that might shape people's views on journalism such as political ideology. This article seeks to complement these studies by exploring the impact that a user's news consumption might have on their expectations of journalism. Utilizing data from an online survey among a representative sample of the Flemish audience, we analyse views on adherence to the main professional norms by the Flemish media, and subsequently relate these to news consumption. To grasp the cross- and multi-medial news consumer, we use a news repertoire approach. Flemish news repertoires differ significantly in views on several professional journalistic norms. By linking these distinct news repertoires to their views on professional norms of journalism, we first question how essential these professional norms put forward by journalists really are. Secondly, we discuss if expectations of journalism result in divergent news consumption strategies or vice versa, laying the groundwork for further exploring audience views on professional journalistic norms.
\end{abstract}

Keywords: audience expectations; journalistic roles; news repertoires; trust in journalism; journalism studies

\section{Introduction}

The digital media landscape is characterized by an abundance of media content. This unlimited volume of content is available anytime, anywhere, and immediate. However, human attention has an upper bound of what it can process (Webster 2008). The combination of the abundance of media and our limited attention makes the current media environment mainly defined by choice (Edgerly 2015). The individual user can navigate the content oneself and does this multi- and cross-medially. Following this development, the audience is acquiring a more central role within journalism and our field of research (Ferrer-Conill and Tandoc 2018; Meadows 2013).

What provoked attention of researchers and journalists alike, was the utilization of the audience's freedom of choice by turning away from mainstream journalistic content. In many parts of the world, including in Flanders as the object of this study, trust in news media is declining and the group of news avoiders is steadily growing (Newman et al. 2020). Furthermore, the audience finds its way to non-traditional media, mostly consuming their content online. According to several studies, these factors lead to further fragmentation and polarization of the public (Stroud 2010; Ksiazek et al. 2010). This widens the media gap along sociodemographic characteristics such as age, education level and gender, and along partisan lines, resulting in a luring threat to society (examples: Westlund and Färdigh 2015; Ørmen 2019).

Illogically, audience expectations of journalism remain for a large part unknown. To cite Karlsson and Clerwall (2019, p. 1184): “The opinions of citizens themselves have been 
remarkably absent". Research of the past decade mainly focused on analysing audience expectations within the context of specific cases, for example: focusing on the expectations of German TV news viewers (Heise et al. 2014). Moreover, these studies rarely implement characteristics that might shape people's views on journalism such as political ideology (Riedl and Eberl 2020). This study seeks to complement these studies by exploring the impact that a user's news consumption-as an essential characteristic - might have on their expectations of journalism.

The importance of knowing and understanding audience expectations of journalism makes us able to better comprehend the role of journalism in society. Following Hanitzsch and Vos' (2017) description of journalism as a discursive institution, journalism stands or falls by the shaping of the audience. "Journalism exists because and as we talk about it", to summarize their vision (Hanitzsch and Vos 2017, p. 129). The public therefore does not only have the power of choice to shape journalism, but also through their expectations, they are able to give journalism their reason of being. The public legitimizes the existence of journalism and of course acts as an essential economic dimension, enabling journalism to function (Vos et al. 2019). Research evinces that journalism tries to anticipate audience expectations and adapts redactional decisions to suit the needs and desires of their audience, assuming, of course, they know their audience (Coleman et al. 2012).

Approaching media use from a media repertoire perspective to be able to truly grasp the media user in a multi- and cross-medial manner (Hasebrink and Popp 2006), we have identified five typologies of news users: incidental news users, traditional news users, online news users, news avoiders, and news omnivores. Already thoroughly discussed in many other studies, we briefly discuss the differences of these five typologies on sociodemographic characteristics, being age and education level, and political preference (examples: van Rees and van Eijck 2003; Peters and Schrøder 2018). We predominantly utilize this media repertoire approach to further analyse audience expectations of journalism and to link these potential differing expectations with media use.

Hallin and Mancini (2004) describe the main purposes of journalism as being informative, acting autonomously and scrutinizing power. The association between publics' views on 'good journalism' and news media use is already discussed (Gil de Zúñiga and Hinsley 2013). Analysing our data of a representative sample of a democratic corporatist region (Hallin and Mancini 2004) such as Flanders, the object of this study, with a media repertoire approach, we try to further expose and explain audience views on the so-called essential professional norms journalists uphold.

\subsection{Journalistic Professional Norms}

Before describing potential discrepancies in the expectations of journalism of the different typologies of news users identified among the Flemish public, we first explore the essential journalistic professional norms. Journalism tries to differentiate itself through those professional norms from other content creators, such as bloggers or politicians (Deuze 2005). The professional norms can be translated into guidelines, written or sometimes unwritten, to make daily work feasible (Brants and de Haan 2010). In a way, they both have a practical dimension and a shared normative or ideological dimension for professional journalists (Deuze 2005).

They broadly fall under three categories: being informative, acting autonomous and scrutinizing power (Hallin and Mancini 2004). First, journalists' main role is informing the public, with an obligation of doing this in a reliable and ethical way. The information must be obtained through a subset of rules, for example, the protection of sources, and retrieval of this information via legal and ethical ways. The information must be brought to the public in a manner of objectivity, neutrality, separation between advertising and editorial content, between facts and opinions, and representing both sides of a story or argument. Above all, the information is expected to be public good and good for the public; in other words: it must be in the public interest and not necessarily what the public is interested in (Hallin and Mancini 2004). 
Secondly, scrutinizing those who are in power and as so taking a stance against detrimental decisions affecting citizens in particular and the society as a whole. This acting as a so-called watchdog is most exemplary in investigative journalism, where multinationals or politicians are judged on their wrongdoing or wrong saying, initially invisible or unknown to the general public. This journalistic purpose closely relates to the third professionalism norm of being autonomous (Hallin and Mancini 2004). Autonomy from powerholders and not abiding to internal influences, such as the board of directors or the marketing department, and external influences, such as politicians or commercial companies, is of utmost importance to bring reliable information and to be able to scrutinize powerholders in a credible way. This idealized view of the press as an institution that operates independently from private and political interests and tries to hold power to account is central to many journalists' self-conception (Palmer et al. 2020). Due to journalism's central role in society, it feels obliged to adhere to these high standards (Fawzi and Mothes 2020). Research has mainly focused on the professional role and norms of journalists from a production perspective (Hanitzsch and Vos 2018; Hanusch 2019; Hanusch and Hanitzsch 2017); audience views and opinions stay for a large part in the shadows (Tandoc and Duffy 2016).

These three essential professional norms-reliable information, autonomy, and watchdog-obviously do not entail the full set of norms. Although, they comprise journalism's role in society and its contribution to a functioning democracy. Journalistic norms have been an anchor point to investigate the publics' expectations (example: Tsfati et al. 2006) and recent findings already indicated that media users expect journalists to fulfil these journalistic roles (Banjac and Hanusch 2020). Therefore, we assume them to be convenient and suitable concepts to compare views on journalism of different types of news users.

\subsection{Audience Views on Journalistic Norms}

To comprehend audiences' expectations from journalism and point out the importance of analysing this, it is important to delineate our current media landscape. The most fitting description of the media landscape is the possibility of the media user to choose which content to consume and which to not (Edgerly 2015). The uprise of digital media, especially the worldwide web, in the 21st century paved the way for the rapid distribution of content of all sorts and kinds. Nowadays, media organizations and users produce and share a never-ending stream of content, accessible to everyone with a simple internet connection. Napoli (2011) describes this abundance of content as being accessible anytime, anywhere and at the blink of an eye. Not only mainstream content but also niche content finds a way to reach a dedicated audience. If you want to keep up with the latest trends in fashion, see a recent movie or one from a couple of decades ago, be informed about state policy or political scandals, or keep up to date with current affairs, the available content is limitless and can be consumed in an exuberant number of ways (Shehata 2016).

Choosing to consume a certain kind of media content implies not being able to consume another kind of media content. People of course only have $24 \mathrm{~h}$ a day and the attention able to give to media is limited. In the so-called 'attention economy', the competition between all kinds of offerings, including media organizations, is seemingly black or white (Lanham 2006). Every moment of the day, an abundance of content crosses swords to win, and in the best case to retain our attention. Traditional news media outlets are competing for the audience's attention with a growing number of adversaries (Shehata 2016).

Subsequently, digital media gave the public possibilities to connect or disconnect, and to consume or avoid information (Costera Meijer and Kormelink 2014). The audience have claimed their freedom of consuming media whenever and wherever, but most importantly, whatever content they want. According to Prior (2007) we have come from a media setting of low-choice and evolved to a high-choice media setting, thriving on individual preferences and interests. Especially social media, being a central place of our information consumption, gives individual users even more latitude to construct their own hub of content, catering to their needs and desires (Merten 2020). 
This freedom of choice and abundance of content also comes with a flipside. Several researchers voiced their concerns and evinced the democratic implications of the individualistic media consumption era we entered (Tewksbury 2005; Webster 2005). According to a vast amount of research, the public will further fragmentize and polarize because of distinct media diets, not to be mistaken with polarization along partisan and ideological lines ( Bennett and Iyengar 2008). The people who seek out news and the people who try to avoid news altogether grow apart because of a widening information and political knowledge gap (Bennett and Iyengar 2008; Aalberg et al. 2013; Ksiazek et al. 2010). Additionally, more recent studies have emphasized these problematic evolutions (Schwarzenegger 2020). Consuming news and having basic knowledge about politics are deemed essential for being an engaged and foremost informed citizen (Shehata 2016; Milner 2002). With the number of news avoiders growing in recent years (Newman et al. 2020), it already became clear that this not only could be problematic for keeping up to date about what is going on in their proximity and in the rest of the world. A recent study showed these avoiders were less aware of the evolution of the coronavirus crisis and showed less support for the measurements taken by the government to suppress the virus, making it potentially disruptive and destructive for our public health and society (Boekee and van der Veer Neil 2020). Although, other studies signalled that the polarization of news audiences could be overestimated (Elvestad et al. 2014; Webster 2014).

Due to the characteristics of the current media landscape and everything it sets in motion, the audience has evolved into a very disruptive force, shaping journalism to their own needs, interests, and standards. However, a consensus still exists of what is seen as 'good' journalism (Gil de Zúñiga and Hinsley 2013) and that the public expects more from professional journalists than from non-professional journalists (Nah and Chung 2011). What this 'more' comprises remains unclear. Several studies have concluded discrepancies between audience expectations of journalism and journalists' own role orientations (Tsfati et al. 2006; Willnat et al. 2019; Loosen et al. 2020), although lacking consensus on the shape these differences take. On the other hand, several studies both revolving around cases (Heise et al. 2014; Nah and Chung 2011; Schmidt and Loosen 2015) and representative samples (Heider et al. 2005; Loosen et al. 2020; Tsfati et al. 2006; Vos et al. 2019; Willnat et al. 2019) have concluded that bringing reliable information, being autonomous and acting as a watchdog are among the audience's expectations put forward as of utmost importance for professional journalists to adhere.

\subsection{A News Repertoire Approach}

Knowing the audience's expectations is an important first step; however, 'the audience' does not exist. Every media user has their personal characteristics, such as gender, age, education level, political preference and so forth. These are characteristics that make us unique, but also bond us with other media users. These sociodemographic characteristics form an important predictor for differences in audience expectations from journalism (Vos et al. 2019; Willnat et al. 2019; Loosen et al. 2020). Another important characteristic is media use itself. By using certain media, people make choices, reflecting their preferences and expectations of the media.

Studies have indicated that high news consumers have higher expectations of journalism (van der Wurff and Schoenbach 2014; Willnat et al. 2019). These studies utilize news consumption as a single variable. As already described in the previous part of this article, media use itself is a characteristic that both enables us to categorize media users and distinguish these categories from each other. The difficulty, though, remains in composing a detailed picture of media users, certainly because media consumption has become more and more multi- and cross-medial, where the media user searches his own way through the "media manifold" (Couldry and Hepp 2016, p. 55).

According to Bjur et al. (2014), researching cross-media consumption is possible from three perspectives: functional differentiation (different media complement and coexist), location ensembles (situational perspective), and media repertoires (personal constellations 
of media). In our study design, we opt for the latter. Media repertoires aid us in figuring out how people are being news consumers in a transformative, digital age (Peters and Schrøder 2018). The term 'media repertoires' was introduced at the start of the 21st century, also becoming a part of the standard lexicon of the media industry. Studying cross-media consumption, and as such media repertoires, is proclaimed to be more relevant in the current high-choice media landscape but is in essence not "new" (Peters and Schrøder 2018). In this article, we follow Hasebrink and Hepp, defining media repertoires as "the entirety of different media that a person regularly uses and can be regarded as relatively stable cross-media patterns of media practices" (Hasebrink and Hepp 2017, p. 367). In this article, we focus solely on news consumption; therefore, 'news repertoires' are a more suitable way in describing the different typologies set out in the Results section (Peters and Schrøder 2018; Ksiazek et al. 2019).

\subsection{Research Questions}

From a news repertoire perspective, we analyse potential differences in expectations of professional norms journalists are eager to put forward as their differentiator from all other informational content creators spread throughout the media landscape. We do this by discussing following research questions:

- $\quad$ Research Question 1 (RQ1): Which news repertoires can we identify among the Flemish population? How do they differ concerning age, education level and political preference?

- $\quad$ Research Question 2 (RQ2): How do these news repertoires differ in expectations of journalists adhering to their main professional norms?

In the first part of the Results section, we define the five distinct news repertoires, giving the most important media and types of news brands they consult to keep up to date. Next, these news repertoires are briefly compared in terms of social stratification, with age and education level being declared as the key sociodemographic characteristics concerning media use. Touching upon potential differences in political differences offers us a slight grasp of proclaimed audience polarization along partisan lines within the context of the Flemish media landscape. The focus is imposed on comparing the news repertoires' views on professional journalistic norms. In this way, the current article endeavours to partake in the debate around the relationship between the consumption of news and trust in news media, bringing an audience perspective on the main professional norms of journalists, utilizing a media repertoire approach.

\section{Methodology}

\subsection{Probing a Representative Sample of Flemish Media Users}

The collection of data ${ }^{1}$ took place between November 15 and December 15 of 2019. With an online survey, we questioned 1577 Flemish respondents on their media use and attitudes towards media, with a strong focus on news media. The survey consisted of five sections: (A) sociodemographic characteristics, (B) internet and media use, (C) trust in media, (D) news brand values and (E) political preferences. The sample is representative for the Flemish population on gender, age, education level and province (STATBEL n.d.). The age limit to partake in the survey was 16 years old, and the oldest person was 75 years old. Concerning gender, the division was almost fifty-fifty, with a very small portion ticking X (=unspecified gender). We questioned education level on a scale ranging from (1) primary school to (11) finishing a PhD. We chose to categorize education level in low, ranging from primary school to finishing the first degree of secondary school, medium, ranging from finishing secondary school to not acquiring a degree in higher education, and high, ranging from obtaining a Bachelor's degree to finishing a PhD. Table 1 shows the distribution of the basic sociodemographic characteristics of our sample. 
Table 1. Distribution of age, gender and education level of our sample ( $\mathrm{N}=1577)$.).

\begin{tabular}{cccc}
\hline Sociodemographic & & Percentage & Frequency \\
\hline \multirow{2}{*}{ Age } & $16-34$ & $29.2 \%$ & 460 \\
\cline { 2 - 4 } & $35-54$ & $35.7 \%$ & 563 \\
\cline { 2 - 4 } & $55-75$ & $35.2 \%$ & 554 \\
\hline \multirow{2}{*}{ Gender } & Male & $51.3 \%$ & 809 \\
\cline { 2 - 4 } & Female & $48.5 \%$ & 765 \\
\hline Education level * & $\mathrm{X}$ & $0.2 \%$ & 3 \\
\cline { 2 - 4 } & Low & $19.7 \%$ & 311 \\
\cline { 2 - 4 } & Medium & $48.8 \%$ & 470 \\
\hline
\end{tabular}

*0.7\% ( $\mathrm{n}=11)$ did not answer this question.

Flanders, as the northern part of Belgium, is situated in western Europe. It is one of the three linguistic communities, besides the French-speaking and the German-speaking. Due to several state reforms, the community authorities were given powers to regulate the radio and television broadcasting markets. Therefore, the communities have their own media law and media regulators. Distinct media markets exist, also from an economic point of view, with media companies focusing usually on servicing one language community. Logically, we focus in this article on one region, being the Dutch-speaking region of Flanders. Five media companies dominate the Flemish media landscape, among which is a strong public service media (Hendrickx et al. 2021).

Hallin and Mancini categorize Belgium in their 'Comparing Media Systems', hence also Flanders, as a democratic corporatist model. "This model displays a high reach of the press market, relatively high degrees of political parallelism, strong professionalization, and strong state intervention, in the form of strong public service broadcasters and subsidies for the press" (Hallin and Mancini 2004 in Brüggemann et al. 2014, pp. 1042-43). Flanders is currently governed by a tripartite: a right-wing, conservative party (N-VA), a liberal party (Open VLD) and a Christian Democratic party (CD\&V). It is also important to point out, COVID-19 was not yet in the picture in Belgium. As other studies concluded, the pandemic, resulting in the disruption of our daily lives, also impacted the output of (news) media and media consumption drastically (Vandenplas et al. 2021, unpublished manuscript).

\subsection{Cluster Analysis to Construct News Repertoires}

To answer our first research question (RQ1), we opted for cluster analysis to construct our news repertoires. Hasebrink and Popp (2006) describe this way of categorizing media users, who have mutual characteristics concerning media use, but also differ distinctly from other media users, to be the most suitable way of coming to a set of repertoires. A specific mode of cluster analysis is latent class analysis (LCA). Building forth on the repertoire approach set out by Hasebrink and Domeyer (2012), this kind of clustering puts the user front and centre. LCA clusters users not based on variables, but on how they have responded on these variables (Collins and Lanza 2010). Other advantages are the possibility of implementing the combination of categorical and continuous variables into the model, and presenting several goodness-of-fit statistics, making the "optimal number of clusters to be identified more arbitrary" in comparison to other clustering methods (Hagenaars and McCutcheon 2002, p. 2; Schreiber and Pekarik 2014; Oser et al. 2013, p. 94; Vandenplas and Picone 2021).

The clustering consists of the following variables or questions: (1) how frequently do you consume the news via: television; radio; newspapers; magazines; websites/applications; social media; and search engines? And: (2) how frequently do you consume the news via a given list of Flemish news brands? Both questions were answered on a Likert scale. In our 
analysis, we have adapted the scale of the first question to daily; weekly; seldom/never, and the scale of the second question to frequently; sometimes; seldom/never to better differentiate between regular and non-users of a certain platform or brand. Looking at the different ways of consuming news, it depends on the medium whether we categorize a user as a frequent user or not. Radio and TV have a rather daily frequency, but magazines have in that sense a more weekly frequency of use. Looking at brands, it follows the logic that people who indicate they use the brand frequently are regular users of the brand. The list of news brands in question (2) consists of 17 Flemish news brands, including the 15 most used news brands in Flanders and two niche, upcoming news brands (CIM 2019). These are logically grouped in following categories: highbrow, lowbrow, regional, mainstream, magazines, and alternative.

\section{Results}

\subsection{Five Distinct News Repertoires}

After clustering with latent class analysis, we were able to construct five distinct news repertoires, consisting of three typologies with a reasonably 'normal' amount of news consumption: incidental news users, traditional news users, and online news users. These contribute to nearly three fourths of the Flemish respondents, leaving a little more than $20 \%$ for two typologies with a reasonably 'extreme' amount of news consumption: news omnivores and news avoiders. Table 2 shows the distribution of these distinct Flemish news repertoires for our sample.

Table 2. Distribution of our five identified news repertoires (total $n=1577$ ).

\begin{tabular}{ccc}
\hline News Repertoire & Percentages & Frequency \\
\hline Incidental news users & $28 \%$ & 441 \\
\hline Traditional news users & $26 \%$ & 410 \\
\hline Online news users & $23 \%$ & 364 \\
\hline News avoiders & $12 \%$ & 189 \\
\hline News omnivores & $11 \%$ & 173 \\
\hline
\end{tabular}

\subsubsection{Incidental News Users}

The largest group of respondents belong to the category of incidental news users. These people consume news mainly via television, radio, and social media. In the current media landscape, as already described above, an abundance of news intrudes our daily lives. The incidental news user does not often choose to consume news content, but stumbles upon news partially unwillingly, by switching channels while watching television, by listening to radio while at work or driving their car, or by scrolling through their feeds on social network sites (Kümpel 2020). Especially news shared on social network sites by friends or acquaintances is hard to not come across while scrolling through feeds on Facebook, Twitter, or other social network sites (Fletcher and Kleis Nielsen 2018). The Flemish incidental news user indicates seeing news predominantly from mainstream and lowbrow news brands, being likewise the brands most present on television and radio and having the most followers on social media (CIM 2019).

\subsubsection{Traditional News User}

The traditional news users consume news mainly via the traditional media, tuning in to the news on television and listening to news on the radio almost daily. More than three fourths read the paper at least once a week, and also magazines are still fairly popular among these traditional news users. Although they mostly get their news from traditional media, their news consumption is broader, and they actively seek news by surfing the websites of newspapers and using search engines. In this sense, the traditional news user has a broader news repertoire than solely relying on television, radio, or print; however, 
they are the only typology still preferring these traditional forms of news media. The mainstream and lowbrow Flemish news brand are the most consumed among this category.

\subsubsection{Online News User}

Due to the digitalization of (news) media, a lot of news users shifted to online news consumption (Newman et al. 2020). The online news users are the third largest group, consisting of almost a fourth of the Flemish audience. These news consumers obviously get their news via online media, via sites of all sorts of newspapers, via social media and using search engines being the most popular ways of news consumption. Slightly more than half of the online news users still consume news via television or radio; in contrast, print press has been deleted almost completely from their news diet. The most consulted Flemish news brands are the mainstream and lowbrow brands; however, this is a lot less than the traditional news users.

\subsubsection{News Avoider}

Ksiazek et al. (2010) conceptualizes news avoiders as those who consume relatively little news, spend almost no time watching cable TV news channels, and avoid news magazines and news websites entirely. In Flanders, this is a relatively small group of news users, although, news avoidance has also risen in Belgium, as in most parts of the world (Newman et al. 2020). The freedom of consuming media content has paved the way for a group of people to cut news content out of their media repertoire. Different reasons are put forward; we have already mentioned the dual edged sword of digital media distributing content that caters to every individual's needs, but also giving them the opportunity to stay away from content that does not interest them in any way. This freedom also nudges the news avoiders towards more relaxing and entertaining forms of media (Prior 2007), starkly contradicting with the, according to them, depressing and frustrating influence of news content, and questioning the unbiasedness and reliability of this content (Strömbäck et al. 2018; Toff and Nielsen 2018). These news avoiders only sporadically encounter news while watching TV, listening to the radio or scrolling through their SNS feeds. As a result, none of the news brands in the survey are frequently used by this news repertoire.

\subsubsection{News Omnivore}

News omnivores, also known as news junkies or news hounds, actively seek out news from a vast array of sources providing them with all kinds of informational content (Kim 2016). The Flemish news omnivores indicate consuming news from all questioned media types in the survey. This also translates in the variance of news brands they consult frequently, being the only category who consume alternative brands, but still in a limited amount.

\subsection{Social Stratification}

Already emphasized by many other researchers, age and education level have an essential impact on media use (examples: van Rees and van Eijck 2003; Peters and Schrøder 2018). In this section, we describe these essential characteristics for our five identified news repertoires and highlight differences between them. Subsequently, we do the same for the political preferences of these news repertoires. Table 3 provides the mean age, education level and political preference.

Table 3. Mean age, education level and political preference of the five news repertoires. (Age in years; education level on a scale from 1 up to 11; political preference on a scale from 1 up to 3 ).

\begin{tabular}{cccccccc}
\hline & Incidental & Traditional & Online & Avoider & Omnivore & Total \\
\hline Age & 54.09 & 50.00 & 38.73 & 42.12 & 37.37 & 46.31 \\
\hline Education level & 4.97 & 5.29 & 4.90 & 4.95 & 5.20 & 5.06 \\
\hline Political preference & 2.17 & 2.05 & 2.15 & 2.07 & 2.04 & 2.11 \\
\hline
\end{tabular}




\subsubsection{Age}

The incidental news users compose the oldest news repertoire, being on average a little over 54 years old. They differ approximately 4 years with our second oldest repertoire, the traditional news users. This type of news user has a mean age of 50. Among our five categories, the news avoiders are in the middle concerning age, with a little over 42 years old on average. The youngest news repertoire are the online news users, with a mean age of almost 39, and the news omnivores, with a mean age of approximately 37 . An analysis of variance (ANOVA) and the post hoc Tukey test results in significant differences in age between almost every typology of news repertoire. No significant differences in age between the online news users and the news avoiders, and the online news users and the news omnivores are observed.

\subsubsection{Education Level}

Education level in our survey ranges from having followed no formal education (1) to having obtained a $\mathrm{PhD}$ (11). On this scale going from 1 up till 11, all our identified news repertoires gravitate around the 5-point mark. None of the news repertoires therefore consist of large number of respondents with either only lowly or highly educated people. Hence, doing the same analysis of variance (ANOVA) and the post hoc Tukey test, we find almost no significant differences between our repertoires of Flemish news users on education level. The only significant differences are observed between the traditional news users and online news users.

\subsubsection{Political Preference}

Asking our respondents about their political preference, they indicated if they categorize themselves as a left-wing (1), centre (2) or right-wing (3) voter. All our news repertoires gravitate around the centre. Interestingly, we do not see any significant differences in political preference between the five news repertoires.

\subsection{Trust in Journalistic Norms}

As described in the first part of the Results section, these distinct repertoires of media users vary significantly in how they consume, or do not consume news. Answering our second research question (RQ2), we look at how they differ in views on the main journalistic norms, discussed in the literature review. The public could perceive the adherence of journalists to these professional norms in a distinct way. An already visible way users can express their opinions on this issue is by turning away from media organizations that they do not think that uphold these journalistic norms, by cancelling their subscriptions and/or not consuming their content (Brants and de Haan 2010). Other possibilities are giving negative reviews or putting comments under articles that question the truthfulness of the information or the independence of the publisher. The possibility of the audience to easily turn away from certain media makes their evaluation of the provided content a potential disruptive force in journalism. As it is difficult for a citizen to scrutinize every aspect of adherence to these journalistic norms, it mostly comes down to trust in the upright acting of the media industry.

Trust and reliability have always been and still are key aspects of informational content (Hovland and Weiss 1952; Tandoc et al. 2018). Nowadays, trust in institutions such as the media is put under pressure, with "fake news" and "post-truth" politics as trending terms used to emphasize the changing relationship between journalism and the public (Tandoc et al. 2018). Several studies pointed out the drop in trust of a growing number of people in the media industry, with especially legacy media taking the hardest blows (Fletcher and Park 2017). The rise of partisan alternative online media in combination with the exponential spread of disinformation contributes to a growing number of people distrusting mainstream media (Figenschou and Ihlebæk 2019; Schwarzenegger 2020). These sceptics seemed to turn away from mainstream media and completely shift to nonmainstream media. This evolution is deemed problematic because narrowing down 
on the number of sources and/or platforms to consume news further contributes to a decline in trust in the mainstream media. As already mentioned above, these people also become less knowledgeable of what is going on in the world and about politics (Bennett and Iyengar 2008; Elvestad et al. 2014; Ksiazek et al. 2010).

Although recent studies have nuanced the relationship of media trust and media use, it remains unclear on which level trust, or the lack of trust, influences the audience of using or turning away from mainstream journalism. Tsfati and Cappella (2003) concluded that people consume news they barely or completely do not trust. More specifically, the question that stays unanswered is if people turn away from news or adapt their news consumption in relation to trusting the adherence of journalists to their professional norms.

To grasp the relation between media use and trust in adherence of professional journalistic norms, we compare the five distinct news consumption typologies in the next section on three main questions, each separately linked to the broad professional norms set out by Hallin and Mancini (2004). These questions closely relate with questions from the Reuters Institute for Journalism's Digital News Report (Newman et al. 2020). The respondents must indicate their trust in these professional norms on a 5-point Likert scale, ranging from 'I do not agree at all' to 'I completely agree'.

The first main professional norm we analyse is providing reliable information. We have distinguished between a general trust in journalists providing reliable information, trust in news that they deliberately consume in providing reliable information and trust in news via social media in providing reliable information. Secondly, we analyse acting autonomously from external influences, split up in political and commercial influences. The final main professional norm is taking up their role of watchdog and scrutinizing those in power. In the next section, we describe the news users with distinct repertoires their trust in the adherence of journalism to these professional norms.

First, we look at the trust of our whole sample. The Flemish media user scores quite highly in news media adhering to journalistic professional norms, with general trust in reliable news scoring a little bit higher than 3.53 points on a maximum of 5 . Looking at the reliability of news they deliberately consume, the score is on average 0.15 points higher. News reaching the Flemish media users via social media scores significantly less than the others, with only 2.8. The independence of political influences scores 3.2 on average, and the independence of commercial influences also scores 3.2. Acting as a watchdog has an average of 3.3 out of 5 . No large differences are observed between the main professional journalistic norms, except for news via social media providing reliable information (see Table 4).

Table 4. Average trust scores of the Flemish public in adherence of journalism to their professional norms. (Scale ranging from 1 up to 5).

\begin{tabular}{ccccccc}
\hline & \multicolumn{2}{c}{ Providing Reliable Information } & \multicolumn{2}{c}{ Acting Autonomous } & Acting as Watchdog \\
\hline & General & Consumed & Social media & Political influence & Commercial influence & \\
\hline Flemish media user & 3.53 & 3.68 & 2.85 & 3.25 & 3.18 & 3.30 \\
\hline
\end{tabular}

3.3.1. Trust of Flemish News Users with Distinct News Repertoires in Journalism Adhering to Their Professional Norms

The incidental news user scores on average 3.79 on general trust in news media providing reliable information. Hence, they score 0.3 points higher than the average of our total sample. If we look at the news incidental news users deliberately consume, they rate this 0.1 point higher than in general. Trust in providing reliable information via social media scores 2.86, comparable with the score the average Flemish media user gave. Trust in having independence from external political influences is on average a 3.26, and from external commercial influences is 3.20. They rate trust in taking up the role of watchdog on average a 3.27 . 
The traditional news user has on average a trust score in providing reliable information: in general, a 3.67, on news they deliberately consume, a 3.81, and on news via social media, a 2.85. Independence from political and commercial external influences scores, respectively, a 3.32 and a 3.33. Looking at trust in acting as a watchdog, the traditional news user gives a score of 3.27 .

The online news user rate trust in providing reliable information in general, a 3.33, 3.46 on trust in providing reliable information they deliberately consume, and a 2.84 on trust in providing reliable information via social media. Trust in independence from external influences gets a 3.19 on remaining independent from political external influences and a 3.05 for commercial external influences. The online news users give a score of 3.26 on trust in acting as a watchdog.

The news avoiders give a score of 3.38 on trust in providing reliable information in general, for deliberately consumed news it is slightly higher, with an average score of 3.46, and for news via social media, it is only 2.67. They also give relatively low scores of trust in independence from political and commercial external influences, with a respective score of 3.06 and 2.96. They rate trust in journalism acting as a watchdog 3.24.

The news omnivores rate providing reliable information in general a 2.97 , news they deliberately consume a 3.35, and via social media, 3.01. Remaining autonomous from external, both political and commercial, obtains a score of 3.36 and 3.27, respectively. The trust of omnivores in journalism acting as a watchdog scores a 3.32 on a maximum of 5 .

Table 5 provides the mean scores of the Flemish news repertoires on the main professional journalistic norms.

Table 5. Mean scores of the different types of news repertoires (scale ranging from 1 up to 5).

\begin{tabular}{|c|c|c|c|c|c|c|c|}
\hline & & Incidental & Traditional & Online & Avoider & Omnivore & Tota \\
\hline \multirow[t]{3}{*}{$\begin{array}{l}\text { Providing reliable } \\
\text { information }\end{array}$} & General & $3.80^{\mathrm{a}}$ & $3.69^{a}$ & $3.33^{b}$ & $3.38^{b}$ & $2.97^{\mathrm{c}}$ & 3.53 \\
\hline & Consumed & $3.93^{a}$ & $3.81^{\mathrm{a}}$ & $3.46^{b}$ & $3.46^{b}$ & $3.35^{b}$ & 3.68 \\
\hline & Social media & $2.86^{a}$ & $2.85^{\mathrm{a}}$ & $2.84^{\mathrm{a}}$ & $2.67^{b}$ & $3.01^{b}$ & 2.85 \\
\hline \multirow[t]{2}{*}{$\begin{array}{l}\text { Independence from } \\
\text { external influences }\end{array}$} & Political & $3.26^{a b}$ & $3.32^{\mathrm{a}}$ & $3.19^{a b}$ & $3.06^{b}$ & $3.36^{\mathrm{ac}}$ & 3.25 \\
\hline & Commercial & $3.20^{\mathrm{ab}}$ & $3.33^{a b}$ & $3.05^{\mathrm{ac}}$ & $2.96^{\text {acd }}$ & $3.27^{\text {abe }}$ & 3.18 \\
\hline Watchdog & & $3.27^{\mathrm{a}}$ & $3.38^{a}$ & $3.26^{\mathrm{a}}$ & $3.24^{\mathrm{a}}$ & $3.32^{\mathrm{a}}$ & 3.20 \\
\hline
\end{tabular}

The same superscript indicates that no significant differences are observed between the news repertoires.

3.3.2. Comparison of Flemish News Users with Different News Repertoires on Professional Journalistic Norms

The first main professional norm of journalists we have analysed is providing reliable information. We have distinguished between a general trust in journalists providing reliable information, trust in news that they deliberately consume in providing reliable information and trust in news on social media in providing reliable information. In trusting journalists to bring reliable information, in general, we see a significant difference between almost all news repertoires except the incidental and traditional news users, and the online news users and news avoiders do not differ significantly. The incidental news users have the most trust in providing reliable information and remarkably, the news omnivores have the least trust in the adherence to this professional journalistic norm.

Similar results are observed in comparing their means on trust in providing reliable information in consumed news. However, no significant differences are observed between the online news users and the news avoiders and news omnivores. All our news users in this case have a relatively high trust in the provided information of news they deliberately consume, even the news omnivores. Additionally, no significant differences between the avoiders and the omnivores are observed. In trusting news to provide reliable information 
via social media, only the news avoiders and omnivores differ significantly. On this professional journalistic norm, the news omnivores give the highest rating, the news avoiders the lowest.

The second main professional journalistic norm is acting autonomously from powerholders. Here, we have distinguished between trust in journalists acting independently from commercial influences and political influences. There is a significant difference between the traditional news users and the online news users and news avoiders on trust in acting autonomously from commercial influences, with the traditional news users giving the highest trust scores and the other two giving the lowest. The news avoiders and news omnivores significantly differ from each other. On trust in acting autonomously from political influences, avoiders and omnivores also differ significantly. They follow the same logic as with the previous journalistic norms, with the omnivores having the most trust and the avoiders the least. A significant difference is also observed between traditional news users and news avoiders.

The final professional journalistic norm is acting as a watchdog. We have not observed any significant differences between the news repertoires. All, as previously stated, rate it in a range between 3.2 and 3.4. Table 5 shows the mean scores and indicates significant differences.

\section{Discussion}

Our study shows that the Flemish public has a relatively high trust in the adherence of the Flemish news media to professional journalistic norms. The three main journalistic professional norms discussed all score on average a little more than 3 of a maximum of 5 points, apart from providing reliable information via social media. Although these results show the importance of the journalistic professional norms according to the Flemish public, this does not account for the differences between the various subsets of the 'multiple audience' (Loosen et al. 2020). By implementing a news repertoire approach, we were able to categorize the audience along five distinct news repertoires. These news users differ in ways they consume news, both on platforms and sources. One of the strengths of a media repertoire approach, or in this study, a news repertoire approach, is not delimiting one's news consumption to a single variable. This news repertoire approach enables us to construct an individual or group's news consumption in a cross-medial and multi-medial manner. Important to note is that a repertoire is not fixed; it can change over time due to "spatiotemporal dynamics, material factors and social, political, and cultural aspects" (Peters and Schrøder 2018, p. 1084).

The five news repertoires we have identified among the Flemish media users are: incidental news users, traditional news users, online news users, news avoiders and news omnivores. The incidental news users are the largest category and the news omnivores the smallest. We have compared these news repertoires on two sociodemographic characteristics, deemed influential on media consumption (van Rees and van Eijck 2003; Peters and Schrøder 2018). Significant differences between almost every news repertoire are observed on age. Following the logic of other studies, the incidental and traditional news users consist of the oldest news consumers, whereas the online news users and news omnivores are among the youngest in our sample (Ksiazek et al. 2019; Peters and Schrøder 2018). Both the news avoiders and news omnivores are relatively young, which demonstrates on the one hand the growing number of the younger generations turning away from news (Newman et al. 2020), and on the other, a select group of youngsters extremely interested in news, resulting in a potentially dangerous knowledge gap between these 'new' media users (Bennett and Iyengar 2008; Aalberg et al. 2013). Remarkably, almost no significant differences are observed on an education level. Only the traditional news users and online news users differ widely enough to see a significant difference. A possible explanation could be that the online news users consist of young people still studying and not having obtained a degree. Although other studies showed age and education level as essential characteristics for composing one's media repertoire, only age seems to influence the media 
use of our Flemish respondents. Same goes for political preference, where no significant differences could be observed between our news repertoires. We can only guess that political polarization in Flanders does not happen—or just barely-due to differences in news repertoire (Bennett and Iyengar 2008).

The media repertoire approach is not solely utilized to categorize the audience, but also enables us to incorporate media consumption as an essential characteristic, to connect with audience views on professional journalistic norms. In our study, media use-or news repertoires - could be seen as influential on views on professional norms of journalism, especially on the main professional norm, providing reliable information. Significant differences are observed between almost all news repertoires, with the largest differences between the news users with a 'normal' news repertoire, traditional, online, and incidental news users, and the news users with a 'extreme' news repertoire, the omnivores and avoiders.

Providing reliable information in general, the news omnivores gave the lowest rating. They seem more critical for the news media in general, as opposed to news they deliberately consume. Here, they do not rate significantly different than the news users with a 'normal' news repertoire. Remarkably, we have observed no significant differences between the news repertoires on providing reliable information via social media. All of our news users rate this relatively low, and as such do not trust the news that reaches them via social media.

The second main professional journalistic norm we have analysed is acting autonomously from external influences. In this case, we have also observed several news users with distinct news repertoires differing significantly from one another. Both acting autonomously from political and commercial influences obtains the lowest ratings from the news avoiders. They seem overall the most critical news users. On the other hand, we have the news omnivores, with the most trust in journalism acting autonomously from external influences. They seem to have the most trust in the two discussed journalistic professional norms. This demonstrates the impact of the broadness of news users' repertoires on their views on professional journalistic norms.

The third and final professional journalistic norm is acting as a watchdog, thus scrutinizing those in power. We have not observed any significant differences between our identified news repertoires. The problem with this professional journalistic norm could be the lack of media knowledge of the general Flemish public.

All these professional journalistic norms are deemed relatively important for the five distinct Flemish news repertoires. However, the significant differences indicate possible discrepancies between the news repertoires in how they perceive them and/or act upon them. This study, therefore, only demonstrates a relation between news repertoires and professional journalistic norms. Further research should try to clarify the direction of the relationship. Is it people's news repertoire that influences their views on these professional norms or is it their views on these professional norms that influence their news repertoire?

\section{Conclusions}

With this study, we lay groundworks for further exploring audience views on professional journalistic norms. Linking a media repertoire approach with trust in adherence of journalism to their main professional norms, we have tried to partake in both the discussion on the relation of media use and trust in media, as well as bringing the opinions of the audience into the equation of which roles journalists must play in society. However, our results are rather descriptive and will serve as a steppingstone to bring more necessary nuance in both a quantitative and qualitative way. Quantitatively, it could be necessary to compare the impact of other essential characteristics, such as political ideology. Qualitatively, it could be feasible to not only let the audience score a set of professional norms, but more importantly figuring out why they deem certain roles as more essential and which other roles they envision journalism should uptake.

A survey is not the best way to question the frequency and intensity of media consumption. Overestimating and not being able to remember when, how and even which 
media they have consumed can give less accurate results, than, for instance, time diary methods or even more accurate, tracking media use (Prior 2009). This would lead to a better depiction of media consumption patterns in comparison to filling out an (online) survey (Möller et al. 2019 in Geers 2020). Another upheaval when questioning news consumption could be that a large number of people access news outlets, not only to consume hard news but mostly for entertainment purposes (Yang et al. 2020). Hence, taking up preferred news topics would compose a more detailed news repertoire. Still, as long as we do not have access to automated news logging on a large scale or access to cross-platform editorial analytics, surveys still form the best next thing to probe users across a range of media sources and devices.

Future studies could examine these audience's expectations more deliberately and closely, implementing more facets of professional journalistic norms, questioning a broader sample, following up possible changes over time, and carrying out cross-national comparisons. These next steps could help us obtain a better understanding of journalism's norms and roles, and map possible discrepancies between the audience and the media industry, hopefully providing solutions to reconnect the audience with journalism.

Author Contributions: Conceptualiztion, P.T. and I.P.; methodology, P.T. and I.P.; software, P.T. and I.P.; validation, P.T. and I.P.; formal analysis, P.T. and I.P.; investigation, P.T. and I.P.; resources, P.T. and I.P.; data curation, P.T. and I.P., writing—original draft preparation, P.T. and I.P.; writing—review and editing, P.T.; visualization, P.T. and I.P.; project administration, I.P.; funding acquisition, I.P. All authors have read and agreed to the published version of the manuscript.

Funding: For the collection of the data, we have received funding through the Chair of RoulartaVUB.

Institutional Review Board Statement: For the data collection, we collaborated with a market research group. The sub-contract stipulated that the market research group needed to act according to strict ethical and privacy guidelines. (See note 1).

Informed Consent Statement: Informed consent was obtained from all subjects involved in the study.

Acknowledgments: We would like to thank our colleague Ruben Vandenplas for aiding us in setting up the latent class analysis.

Conflicts of Interest: The authors declare no conflict of interest.

\section{Notes}

1 For the data collection, we collaborated with a market research group. The sub-contract stipulated that the market research group needed to act according to strict ethical and privacy guidelines.

\section{References}

Aalberg, Toril, Arild Blekesaune, and Eiri Elvestad. 2013. Media Choice and Informed Democracy: Toward Increasing News Consumption Gaps in Europe? The International Journal of Press/Politics 18: 281-303. [CrossRef]

Banjac, Sandra, and Folker Hanusch. 2020. A Question of Perspective: Exploring Audiences Views of Journalistic Boundaries. New Media E Society. [CrossRef]

Bennett, W. Lance, and Shanto Iyengar. 2008. A New Era of Minimal Effects? The Changing Foundations of Political Communication. Journal of Communication 58: 707-31. [CrossRef]

Bjur, Jakob, Kim Schrøder, Uwe Hasebrink, Cédric Courtois, Hanna Adoni, and Hillel Nossek. 2014. Cross-Media Use: Unfolding Complexities in Contemporary Audiencehood. Oxfordshire: Routledge.

Boekee, Steven, and Hoekstra Hans van der Veer Neil. 2020. De Staat van Nederland 2020: Onderzoek naar de beleving van Nederlanders Rondom de Coronacrisis. Amsterdam: Newcom Research \& Consultancy B.V.

Brants, Kees, and Yael de Haan. 2010. Taking the Public Seriously: Three Models of Responsiveness in Media and Journalism. Media, Culture \& Society 32: 411-28. [CrossRef]

Brüggemann, Michael, Sven Engesser, Florin Büchel, Edda Humprecht, and Laia Castro. 2014. Hallin and Mancini Revisited: Four Empirical Types of Western Media Systems: Hallin and Mancini Revisited. Journal of Communication 64: 1037-65. [CrossRef]

CIM. 2019. Bereik Resultaten 2019. CIM Retrieved 15 January 2021. Available online: https://www.cim.be/nl/pers/bereik-resultaten (accessed on 15 January 2021).

Coleman, Stephen, David E. Morrison, and Scott Anthony. 2012. A constructivist study of trust in the news. Journalism Studies 13: 37-53. [CrossRef] 
Collins, Linda M., and Stephanie T. Lanza. 2010. Latent Class and Latent Transition Analysis: With Applications in the Social, Behavioral, and Health Sciences. Hoboken: John Wiley and Sons Inc.

Costera Meijer, Irene, and Tim Groot Kormelink. 2014. Checking, Sharing, Clicking and Linking: Changing Patterns of News Use between 2004 and 2014. Digital Journalism, 1-16. [CrossRef]

Couldry, Nick, and Andreas Hepp. 2016. The Mediated Construction of Reality. Hoboken: John Wiley and Sons Inc.

Deuze, Mark. 2005. What Is Journalism? Professional Identity and Ideology of Journalists Reconsidered. Journalism: Theory, Practice E Criticism 6: 442-64. [CrossRef]

Edgerly, Stephanie. 2015. Red Media, Blue Media, and Purple Media: News Repertoires in the Colorful Media Landscape. Journal of Broadcasting E Electronic Media 59: 1-21. [CrossRef]

Elvestad, Eiri, Arild Blekesaune, and Toril Aalberg. 2014. The Polarized News Audience? A Longitudinal Study of News-Seekers and News-Avoiders in Europe. SSRN Scholarly Paper. Rochester: Social Science Research Network, ID 2469713.

Fawzi, Nayla, and Cornelia Mothes. 2020. Perceptions of Media Performance: Expectation-Evaluation Discrepancies and Their Relationship with Media-Related and Populist Attitudes. Media and Communication 8: 335-47. [CrossRef]

Ferrer-Conill, Raul, and Edson C. Tandoc Jr. 2018. The Audience-Oriented Editor. Digital Journalism 6: 436-53. [CrossRef]

Figenschou, Tine Ustad, and Karoline Andrea Ihlebæk. 2019. Challenging Journalistic Authority: Media Criticism in Far-Right Alternative Media. Journalism Studies 20: 1221-37. [CrossRef]

Fletcher, Richard, and Rasmus Kleis Nielsen. 2018. Are People Incidentally Exposed to News on Social Media? A Comparative Analysis. New Media E Society 20: 2450-68. [CrossRef]

Fletcher, Richard, and Sora Park. 2017. The Impact of Trust in the News Media on Online News Consumption and Participation. Digital Journalism 5: 1281-99. [CrossRef]

Geers, Sabine. 2020. News Consumption across Media Platforms and Content. Public Opinion Quarterly 84: 332-54. [CrossRef]

Gil de Zúñiga, Homero, and Amber Hinsley. 2013. The Press Versus the Public: What Is “Good Journalism?”. Journalism Studies 14: 926-42. [CrossRef]

Hagenaars, Jacques A., and Allan L. McCutcheon, eds. 2002. Applied Latent Class Analysis. Cambridge: Cambridge University Press.

Hallin, Daniel C., and Paolo Mancini. 2004. Comparing Media Systems: Three Models of Media and Politics. Cambridge: Cambridge University Press.

Hanitzsch, Thomas, and Tim P. Vos. 2017. Journalistic Roles and the Struggle Over Institutional Identity: The Discursive Constitution of Journalism. Communication Theory 27: 115-35. [CrossRef]

Hanitzsch, Thomas, and Tim P. Vos. 2018. Journalism beyond Democracy: A New Look into Journalistic Roles in Political and Everyday Life. Journalism 19: 146-64. [CrossRef]

Hanusch, Folker. 2019. Journalistic Roles and Everyday Life. Journalism Studies 20: 193-211. [CrossRef]

Hanusch, Folker, and Thomas Hanitzsch. 2017. Comparing Journalistic Cultures across Nations. Journalism Studies 18: 525-35. [CrossRef]

Hasebrink, Uwe, and Hanna Domeyer. 2012. Media Repertoires as Patterns of Behaviour and as Meaningful Practices: A Multimethod Approach to Media Use in Converging Media Environments. Participations. Journal of Audience and Reception Studies 9: 757-79.

Hasebrink, Uwe, and Andreas Hepp. 2017. How to Research Cross-Media Practices? Investigating Media Repertoires and Media Ensembles. Convergence 23: 362-77. [CrossRef]

Hasebrink, Uwe, and Jutta Popp. 2006. Media Repertoires as a Result of Selective Media Use. A Conceptual Approach to the Analysis of Patterns of Exposure. Communications 31. [CrossRef]

Heider, Don, Maxwell McCombs, and Paula M. Poindexter. 2005. What the public expects of local news: Views on public and traditional journalism. Journalism \& Mass Communication Quarterly 82: 952-67.

Heise, Nele, Wiebke Loosen, Julius Reimer, and Jan-Hinrik Schmidt. 2014. Including the Audience. Journalism Studies 15: 411-30. [CrossRef]

Hendrickx, Jonathan, Pauljan Truyens, Ike Picone, and Karen Donders. The Media for Democracy Monitor-Country ReportFlanders (Belgium). Retrieved 20 April 2021. Available online: http://euromediagroup.org/mdm/reports/2021 (accessed on 20 April 2021).

Hovland, Carl I., and Walter Weiss. 1952. The Influence of Source Credibility on Communication Effectiveness. Public Opinion Quarterly 17: 635-50. [CrossRef]

Karlsson, Michael, and Christer Clerwall. 2019. Cornerstones in Journalism: According to Citizens. Journalism Studies 20: 1184-99. [CrossRef]

Kim, Su Jung. 2016. A Repertoire Approach to Cross-Platform Media Use Behavior. New Media E Society 18: 353-72. [CrossRef]

Ksiazek, Thomas B., Edward C. Malthouse, and James G. Webster. 2010. News-Seekers and Avoiders: Exploring Patterns of Total News Consumption Across Media and the Relationship to Civic Participation. Journal of Broadcasting \& Electronic Media 54: 551-68. [CrossRef]

Ksiazek, Thomas B., Su Jung Kim, and Edward C. Malthouse. 2019. Television News Repertoires, Exposure Diversity, and Voting Behavior in the 2016 U.S. Election. Journalism \& Mass Communication Quarterly 96: 1120-44. [CrossRef]

Kümpel, Anna Sophie. 2020. The Matthew Effect in Social Media News Use: Assessing Inequalities in News Exposure and News Engagement on Social Network Sites (SNS). Journalism 21: 1083-98. [CrossRef]

Lanham, Richard A. 2006. The Economics of Attention: Style and Substance in the Age of Information. Chicago: University of Chicago Press. 
Loosen, Wiebke, Julius Reimer, and Sascha Hölig. 2020. What Journalists Want and What They Ought to Do (In)Congruences between Journalists Role Conceptions and Audiences Expectations. Journalism Studies 21: 1744-74. [CrossRef]

Meadows, Michael. 2013. Putting the Citizen Back into Journalism. Journalism 14: 43-60. [CrossRef]

Merten, Lisa. 2020. Block, Hide or Follow-Personal News Curation Practices on Social Media. Digital Journalism, 1-22. [CrossRef]

Milner, Henry. 2002. Civic Literacy: How Informed Citizens Make Democracy Work. Medford: UPNE, Tufts University Press.

Möller, Judith, Robbert Nicolai van de Velde, Lisa Merten, and Cornelius Puschmann. 2019. Explaining Online News Engagement Based on Browsing Behavior: Creatures of Habit? Social Science Computer Review. [CrossRef]

Nah, Seungahn, and Deborah Chung. 2011. News Editors Demographics Predict Their Social Capital. Newspaper Research Journal 32: 34-45. [CrossRef]

Napoli, Philip M. 2011. Audience Evolution: New Technologies and the Transformation of Media Audiences. New York: Columbia University Press.

Newman, Nic, Fletcher Richard, Schultz Anne, Andi Simge, and Rasmus Kleis Nielsen. 2020. Reuters Institute Digital News Report 2020. Oxford: Reuters, vol. 112.

Ørmen, Jacob. 2019. Not So Distinct After All: Assessing Social Stratification of News Users on the Web. Journalism Studies 20: 1653-70. [CrossRef]

Oser, Jennifer, Marc Hooghe, and Sofie Marien. 2013. Is Online Participation Distinct from Offline Participation? A Latent Class Analysis of Participation Types and Their Stratification. Political Research Quarterly 66: 91-101. [CrossRef]

Palmer, Ruth, Benjamin Toff, and Rasmus Kleis Nielsen. 2020. “The Media Covers Up a Lot of Things": Watchdog Ideals Meet Folk Theories of Journalism. Journalism Studies 21: 1973-89. [CrossRef]

Peters, Chris, and Kim Christian Schrøder. 2018. Beyond the Here and Now of News Audiences: A Process-Based Framework for Investigating News Repertoires. Journal of Communication 68: 1079-103. [CrossRef]

Prior, Markus. 2007. Post-Broadcast Democracy by Markus Prior. In Cambridge Core. Retrieved 28 June 2019. Cambridge: Cambridge University Press.

Prior, Markus. 2009. Improving Media Effects Research through Better Measurement of News Exposure. The Journal of Politics 71: 893-908. [CrossRef]

Riedl, Andreas, and Jakob-Moritz Eberl. 2020. Audience Expectations of Journalism: Whats Politics Got to Do with It? Journalism. [CrossRef]

Schmidt, Jan-Hinrik, and Wiebke Loosen. 2015. Both Sides of the Story. Digital Journalism 3: 259-78. [CrossRef]

Schreiber, James B., and Andrew J. Pekarik. 2014. Technical Note: Using Latent Class Analysis versus K-Means or Hierarchical Clustering to Understand Museum Visitors. Curator: The Museum Journal 57: 45-59. [CrossRef]

Schwarzenegger, Christian. 2020. Personal Epistemologies of the Media: Selective Criticality, Pragmatic Trust, and CompetenceConfidence in Navigating Media Repertoires in the Digital Age. New Media E Society 22: 361-77. [CrossRef]

Shehata, Adam. 2016. News Habits Among Adolescents: The Influence of Family Communication on Adolescents News Media Use-Evidence from a Three-Wave Panel Study. Mass Communication and Society 19: 758-81. [CrossRef]

STATBEL. n.d. Structure of the Population I Statbel. Retrieved 23 February 2020. Available online: https://statbel.fgov.be/en/themes / population/structure-population (accessed on 23 February 2020).

Strömbäck, Jesper, Kajsa Falasca, and Sanne Kruikemeier. 2018. The Mix of Media Use Matters: Investigating the Effects of Individual News Repertoires on Offline and Online Political Participation. Political Communication 35: 413-32. [CrossRef]

Stroud, Natalie Jomini. 2010. Polarization and Partisan Selective Exposure. Journal of Communication 60: 556-76. [CrossRef]

Tandoc, Edson C., Jr., and Andrew Duffy. 2016. Keeping Up With the Audiences: Journalistic Role Expectations in Singapore. International Journal of Communication 10: 21.

Tandoc, Edson C., Jr., Zheng Wei Lim, and Richard Ling. 2018. Defining “Fake News”. Digital Journalism 6: 137-53. [CrossRef]

Tewksbury, David. 2005. The Seeds of Audience Fragmentation: Specialization in the Use of Online News Sites. Journal of Broadcasting E Electronic Media 49: 332-48. [CrossRef]

Toff, Benjamin, and Rasmus Nielsen. 2018. "I Just Google It": Folk Theories of Distributed Discovery. Journal of Communication 68. [CrossRef]

Tsfati, Yariv, and Joseph N. Cappella. 2003. Do People Watch What They Do Not Trust?: Exploring the Association between News Media Skepticism and Exposure. Communication Research 30: 504-29. [CrossRef]

Tsfati, Yariv, Oren Meyers, and Yoram Peri. 2006. What Is Good Journalism? Comparing Israeli Public and Journalists Perspectives. Journalism 7: 152-73. [CrossRef]

van der Wurff, Richard, and Klaus Schoenbach. 2014. Civic and Citizen Demands of News Media and Journalists: What Does the Audience Expect from Good Journalism? Journalism \& Mass Communication Quarterly 91: 433-51. [CrossRef]

van Rees, Kees, and Koen van Eijck. 2003. Media Repertoires of Selective Audiences: The Impact of Status, Gender, and Age on Media Use. Poetics 31: 465-90. [CrossRef]

Vandenplas, Ruben, and Ike Picone. 2021. Media as the Great Emancipators? Exploring Relations between Media Repertoires and Cultural Participation in Flanders. Convergence: The International Journal of Research into New Media Technologies. [CrossRef]

Vandenplas, Ruben, Truyens Pauljan, Vis Sarah, and Picone Ike. 2021. Tuning Out the News. A cross-Media Perspective on News Avoidance Practices during the COVID-19 Pandemic. Unpublished Manuscript. 
Vos, Tim P., Folker Hanusch, Dimitra Dimitrakopoulou, Margaretha Geertsema-Sligh, and Annika Sehl, eds. 2019. The International Encyclopedia of Journalism Studies, 1st ed. Hoboken: Wiley.

Webster, James G. 2005. Beneath the Veneer of Fragmentation: Television Audience Polarization in a Multichannel World I Journal of Communication I Oxford Academic. Retrieved 29 April 2021. Available online: https:/ /academic.oup.com/joc/article-abstract/ 55/2/366/4103022 (accessed on 29 April 2021).

Webster, James G. 2008. Structuring a Marketplace of Attention. In The Hyperlinked Society: Questioning Connections in the Digital Age. Ann Arbor: University of Michigan Press, pp. 23-38.

Webster, James G. 2014. The Marketplace of Attention: How Audiences Take Shape in a Digital Age. Cambridge: MIT Press.

Westlund, Oscar, and Mathias A. Färdigh. 2015. Accessing the News in an Age of Mobile Media: Tracing Displacing and Complementary Effects of Mobile News on Newspapers and Online News. Mobile Media E Communication 3: 53-74. [CrossRef]

Willnat, Lars, David H. Weaver, and G. Cleveland Wilhoit. 2019. The American Journalist in the Digital Age. Journalism Studies 20: 423-41. [CrossRef]

Yang, Tian, Sílvia Majó-Vázquez, Rasmus K. Nielsen, and Sandra González-Bailón. 2020. Exposure to News Grows Less Fragmented with an Increase in Mobile Access. Proceedings of the National Academy of Sciences USA 117: 28678-83. [CrossRef] [PubMed] 